\title{
A indústria cultural e a política educacional do regime militar: o caso da revista Escola
}

\author{
The culture industry and educational policy in the \\ Military Regime: the case of Escola magazine
}

Maria Rita de Almeida Toledo*

Daniel Revah**

\section{Resumo}

Este trabalho apresenta um estudo sobre a difusão, pela revista Escola, da Reforma de Ensino instituída pela Lei 5.692/71. Lançada pela editora Abril em outubro de 1971, a revista circulou em 27 números e desapareceu em abril de 1974. Seu público-alvo era o professor de $1^{\circ} \mathrm{Grau}$, a quem se oferece como "instrumento de diálogo e cooperação", como instrumento a "serviço da reforma" instituída pela política educacional do regime militar. Neste artigo são analisados editoriais e matérias que aludem à reforma, bem como os principais dispositivos materiais que organizam a revista. O objetivo é evidenciar as estratégias da Editora para difundir um novo produto comercial associando-se à reforma e à sua divulgação. Conclui-se que esse novo periódico busca forjar no campo educacional um novo leitor, afeito aos padrões da indústria cultural.

Palavras-chave: Lei 5.692/71; regime militar; periódico educacional.

\section{Abstract}

This work presents a study of the dissemination in Escola magazine of the Teaching Reform established by Law 5.692/71. Launched by Abril publishers in October 1971, 27 issues were published before it disappeared in April 1974. Its target audience consisted of primary school teachers, for whom it was offered as 'a tool for dialog and cooperation', a tool which was used to 'on behalf of the reform' established by the military regime. In this article reports and editorials referring to the reform are analyzed, as well as the main material devices around which the magazine was organized. The objective is to highlight the publisher's strategies to spread a new commercial product associated with the reform and its publicizing. It is concluded that this new periodical, therefore, tried to forge a new reader in the educational field, who was accustomed to the standards of the cultural industry. Keywords: 5.692/71 Brazilian Act; military regime; educational magazine.

\footnotetext{
* Universidade Federal de São Paulo, Departamento de História. Estrada do Velho Caminho, 333, Bairro dos Pimentas. 07252-312 Guarulhos - SP - Brasil. mra.toledo@unifesp.br

** Doutor, Universidade Federal de São Paulo. revah@uol.com.br
} 
A reforma de ensino instituída pela Lei 5.692/71 fecha um longo ciclo de debates sobre a escola pública brasileira. Desde o final da ditadura instalada com o Estado Novo (1937-1945), as discussões sobre as mudanças necessárias para a expansão da escola secundária, sobre sua função e articulação com o primário, sobre a formação do professor, a organização de sua carreira e de sua jornada de trabalho atravessaram as décadas de 1940, 1950 e 1960. Mesmo com a aprovação da Lei de Diretrizes e Bases da Educação (4.024/61), os debates não se arrefeceram, intensificados pelo movimento estudantil, tanto universitário quanto secundarista, e expandiram-se em torno da reforma universitária.

A nova Constituição estabelecida pelo regime militar em 1967 veio legislar sobre algumas dessas questões, entre elas a redefinição e extensão da escola primária para oito anos. A política educacional iniciada com a referida Constituição consubstanciou-se na Lei 5.692/71, que reordenou as relações entre a escola secundária e a primária, assim como as carreiras dos professores e sua formação, impondo soluções de determinados grupos da contenda, sob forte vigília e repressão do regime militar então instaurado. O debate em torno da nova política educacional, assinada pelo ministro Jarbas Passarinho, foi, de um lado, amordaçado e, de outro, acomodado sob o rótulo da expansão democrática da escola. ${ }^{1}$ As estratégias de implantação, propaganda e acomodação das opiniões em torno da reforma parecem ser inúmeras e pouco investigadas. Propõe-se com este artigo tomar como objeto as estratégias de difusão da reforma 5.692/71 empregadas e ordenadas em impressos. Para tanto, elege-se a revista Escola, editada pelo grupo Abril, cuja distribuição ocorria preferencialmente no circuito das bancas de jornal, à diferença do que se observa na época entre os periódicos destinados ao professor, como os editados por órgãos públicos, associações de docentes e outras editoras comerciais. A própria Abril nasce como um importante grupo empresarial, uma editora comercial de grande porte que investe na produção de impressos para serem difundidos em bancas de jornal.

A revista Escola, lançada em outubro de 1971, circulou em 27 números e desapareceu em abril de 1974. Seu público-alvo era o professor de $1^{\circ} \mathrm{Grau}$, a quem o periódico se oferece como "instrumento de diálogo e cooperação", como um veículo que "entusiasticamente, se coloca a serviço" da reforma, como "uma ponte permanente de comunicação entre todos os professores brasileiros", de modo a colaborar com seu trabalho em sala de aula (Escola, n.0, out. 1971, p.3 e 21). Neste artigo analisam-se editoriais e reportagens sobre atividades em sala de aula em que a reforma de ensino encontra-se implicada, bem como alguns dispositivos materiais que organizam a revista. O objetivo é 
evidenciar as estratégias da editora para difundir um novo produto comercial associando-se à reforma e à sua divulgação.

A perspectiva adotada na investigação enfatizou a relação entre os conteúdos da cultura pedagógica e a materialidade de seus processos de produção, circulação, imposição e apropriação pelos agentes envolvidos. Entende-se que os processos de constituição do impresso, assim como as formas como são postos a circular, são reveladores das estratégias de intervenção no campo da pedagogia e da formação docente, porque esses processos são instituídos pelas representações dos agentes de produção sobre o próprio campo dos saberes pedagógicos, sobre os professores e suas capacidades de leitura, sobre as políticas de ordenação da cultura docente. Revelam, portanto, os agentes que, em lugares de poder específicos, mobilizam e põem em circulação diferentes modelos de impressos. Nesta investigação, pretende-se "analisar o impresso de destinação pedagógica da perspectiva de sua produção e distribuição, como produto de estratégias editoriais em estrita correspondência com os usos que dele são modelarmente prescritos"; trata-se também de "analisá-lo como suporte material de práticas de sala de aula”. Neste segundo caso, portanto, objetiva-se "pensar os usos do impresso na configuração de um modo escolar de regulação das atividades de ensino-aprendizagem". ${ }^{2}$

Toma-se aqui a editora Abril como lugar de poder e querer porque detém um saber específico sobre o outro - o leitor. Para Certeau, esse saber e o poder com ele adquirido permitem ao lugar do próprio esquadrinhar os espaços nos quais atua, transformando as forças estrangeiras em objetos, porque pode observar e medir, controlar e incluir em seu campo de visão os movimentos do outro: lugar capaz de prever o tempo pela leitura do espaço, do seu campo de atuação. ${ }^{3}$ Nesse caso, o saber materializa-se nas estratégias editoriais da revista, que estampa em suas páginas as fronteiras entre campos de saberes, opera a inclusão e a exclusão de autores e obras em territórios delimitados, prescreve a localização de práticas pedagógicas em diferentes campos de conhecimento e situa o seu público no espaço de leitura que desenha, construindo certa geografia da cultura escolar. Os sentidos das práticas editoriais da Abril podem ser detectados na articulação das representações que sustenta da leitura e dos leitores para os quais se destinam seus periódicos, fascículos e outros impressos, bem como na seleções de autores, saberes e práticas de leitura que põe em circulação.

Não se pretendeu, assim, tratar do leitor empírico - aquele que toma os objetos de leitura possivelmente subvertendo sua ordem -, mas do destinatário ideal: aquele para quem o editor constrói cuidadosamente a arquitetura de seu impresso, separando, classificando, distribuindo saberes e práticas nas suas 
páginas, ordenando tempos e espaços de leitura; produzindo capas, paratextos, explicações e reclames destinados ao mercado editorial em que se inscreve. ${ }^{4}$

\section{UMA REVISTA EXPERIMENTAL?}

Em outubro de 1971, no mês em que se comemora o dia do professor, é lançado o número inaugural da revista Escola. A data escolhida para essa primeira edição já chama a atenção para o tipo de público que a revista quer atingir e (re)configurar:

\section{Caro professor,}

Você deve ter estranhado ao receber um zero, quando seu esforço no sentido de difundir a educação merece a nota máxima. Entretanto, pensando em você, e em homenagem a você, é que a Editora Abril está lançando mais esta publicação, cujo número experimental - chamado de número zero - chega hoje às suas mãos. (Escola, n.0, out. 1971, p.3)

Com essas primeiras linhas do editorial inaugural, Victor Civita, o editor, anuncia o caráter experimental desse número, que é extensivo à própria revista. À primeira vista, esse caráter deve-se ao fato de a Editora Abril não ter entre suas publicações uma revista destinada apenas aos professores. A leitura desse editorial, entretanto, indica outros sentidos envolvidos nessa representação. Um deles corresponde à própria materialidade do periódico e está presente na descrição feita por Civita da fórmula editorial empregada nesse novo experimento da Abril:

Acreditamos que pela primeira vez, no Brasil, seja feita uma revista pedagógica com os recursos do jornalismo ou, em outras palavras, com a forma jornalística a serviço do conteúdo pedagógico. É o meio de torná-la não só mais atraente, como de aproveitar os recursos da comunicação num setor que se tem caracterizado pelo mais insistente arcaísmo. (ibidem)

Outra dimensão relativa ao caráter experimental atribuído à revista concerne à sua função: ser um veículo que "entusiasticamente, se coloca a serviço" da reforma implementada pela Lei 5692/71 (idem, p.21). A aposta da Abril, com essa nova publicação, é angariar um leitor que a reforma e a revista (re)configuram conjuntamente: o professor de $1^{\circ}$ grau. Para justificar o novo impresso, Civita argumenta respondendo a uma pergunta que ele próprio formula: 
Por que o ensino de $1^{\circ}$ grau? Porque é nesse setor que se localizam os maiores problemas do ensino; porque é nesse setor que uma publicação pedagógica pode ser útil ao maior número daqueles que têm a responsabilidade de ensinar e, finalmente, porque reside na implantação e no aperfeiçoamento do ensino de $1^{\circ}$ grau a esperança do êxito do gigantesco esforço desenvolvido pelo Governo Federal e pelos Estados no sentido de dar ao país um ensino adequado às suas necessidades presentes e futuras. (ibidem)

Segundo a revista, com a Lei 5692/71 estar-se-ia diante "de algo mais que uma reforma: é uma nova concepção da escola e do ensino" (ibidem). Ao se colocar como instrumento de difusão e propaganda dessa "nova concepção", que ela própria configura, a Abril visa o mercado possibilitado pela lei que cria o professor de $1^{\circ}$ grau. A editora aposta na expansão simultânea da escola de $1^{\circ}$ grau, dos postos docentes e da própria revista. ${ }^{5}$

Nesta análise, portanto, Escola é entendida como modalidade específica de impresso que carrega em sua materialidade dupla estratégia de intervenção cultural: a intervenção editorial que se apropria dos saberes pedagógicos, por meio da forma jornalística, para a ampliação do mercado dos produtos da Abril; como intervenção no campo educacional, divulgando, organizando e prescrevendo as práticas entendidas como necessárias à implementação da reforma 5692/71.

\section{FÓRMULA EDITORIAL}

A revista Escola teve curta duração. Ao todo foram editados 26 números (excluindo o número zero), entre março de 1972 e abril de 1974, mensalmente a partir do ${ }^{\circ} 1$. Várias edições contêm encartes para a composição de dois livros: O Livro da Reforma (nas edições de outubro de 1971 a junho de 1972) e Recursos auxiliares do Ensino (entre novembro de 1973 e abril de 1974).

A fórmula editorial segue algumas diretrizes: o atrelamento da revista à reforma instaurada pela Lei 5692/71, como suporte de sua difusão, por meio da divulgação de sua estrutura legal, dos discursos e opiniões de seus produtores e das bases teórico-práticas de sua implantação, assim como do debate em torno dela; a adaptação da linguagem pedagógica à linguagem jornalística; a seleção de experiências de ensino-aprendizagem bem-sucedidas; a centralidade do discurso sobre a figura do professor e o seu trabalho em sala de aula. ${ }^{6}$

Desses elementos da fórmula editorial, aqui trataremos apenas da linguagem jornalística, que a revista destaca como um grande diferencial em relação 
a outros periódicos educacionais. Como enfatiza o editorial do $\mathrm{n}^{\circ} 1$ da revista: “Ao contrário das publicações convencionais, Escola coloca a serviço da Pedagogia a técnica jornalística, que se tem mostrado eficaz, como instrumento de comunicação, em todos os demais campos do conhecimento" (Escola, n.1, mar. 1972, p.3).

Alardeando o uso dos "recursos do jornalismo moderno e dinâmico", a Abril transforma a Pedagogia em notícia, em crônica do tempo presente (ibidem). ${ }^{7}$ Os seus personagens são professores, alunos, diretores e supervisores, entre outros, sem contar as autoridades do momento. Na revista, o discurso da tradição pedagógica, de seus intelectuais, tende a ser substituído pelos reformadores e pelo presente instituído pelas políticas educacionais da ditadura, qualificadas, sobretudo nos primeiros números, pelos adjetivos criados pela própria propaganda do regime. Segundo a editora, com a reforma "começará uma das mais ambiciosas fases de toda a história do ensino no Brasil" (Escola, n.0, out. 1971, p.3), é o "momento em que o Brasil inicia a implantação da mais audaciosa reforma do ensino de toda a sua história" (Escola, n.1, mar. 1972, p.3). Ressonam aí os slogans do Brasil grande e do país do futuro que a ditadura então promete. Com eles, a Abril sintoniza o leitor com as mudanças do regime militar e envolve-o em suas promessas, conferindo-lhe o lugar de testemunha e agente das "grandes" transformações em curso.

A linguagem jornalística implica também critérios de produção das matérias. Alguns correspondem aos que na época eram evidenciados, por exemplo, no manual intitulado Técnica de jornal e periódico, de Luiz Amaral. ${ }^{8}$ Entre outros aspectos, ele destaca: atualidade, veracidade e interesse humano.

A reforma, no caso, é um apelo ao leitor para ele se manter atualizado diante do que deverá incidir diretamente sobre a sua atuação. Em vários editoriais, destaca-se a importância do "momento" como divisor de águas da educação nacional, e o "momento" é a reforma, lembrada com insistência sobretudo no início, quando a revista apostava no crescimento do seu mercado editorial:

O leitor observará a insistência da revista nos temas relativos à reforma do ensino. Essa colocação intencional da temática de Escola destina-se exatamente a procurar colaborar no debate e divulgação daquilo que se faz de mais importante, no momento, no setor da educação, que é a implantação de uma nova concepção de escola e, por conseguinte, de uma nova concepção do professor. (Escola, n.1, mar. 1972, p.3) 
Prometer a permanente atualização do leitor com os assuntos candentes em cada momento é próprio das revistas comerciais e da fórmula editorial de Escola, com uma linguagem que se vale de diversos recursos para renovar essa promessa a cada nova edição. Esse é o caso da propaganda da revista presente em suas próprias páginas: "Você ficará sabendo o que os outros professores estão fazendo, suas experiências bem sucedidas, novas técnicas de ensino, tudo o que é importante dentro de uma escola" (Escola, n.0, out. 1971, p.21).

A sensação de veracidade é criada por um conjunto de dispositivos, tais como: o anonimato das matérias, ${ }^{9}$ que dá a impressão de neutralidade e de relação direta com os que participam como professores, diretores e autoridades de ensino, cujas falas e comentários vez por outra aparecem de forma direta e destacados por meio de aspas; uso abundante de fotografias, como que atestando as informações descritas e apresentando as personagens nomeadas. Nos editoriais essa sensação de veracidade é produzida pela citação e por comentários das matérias relativas a experiências realizadas em determinada escola e município, com a reforma sendo implantada na própria sala de aula:

Ainda nesse número, chamamos a atenção para a série de reportagens, da primeira à oitava séries, realizada no Instituto Municipal de Educação e Pesquisas, de São Paulo, que pioneiramente introduziu em seus estabelecimentos as normas da reforma, estando em condições de implantar a oitava série, como já implantou, já no início de 72. (Escola, n.2, abr. 1972, p.3)

O interesse humano explicita-se, pode-se dizer, pela constante presença do leitor em suas páginas, pois o foco da revista recai sobre o professor e a sala de aula, os alunos e as questões que o preocupam. Busca-se, assim, criar uma forte identidade entre o leitor e o impresso, à semelhança do que também ocorre nas propagandas que constam na revista. Por exemplo, na propaganda da própria revista veiculada no exemplar $\mathrm{n}^{\circ} 3$, afirma-se: "Escola colocou todos os professores do Brasil em suas páginas: suas experiências, seus problemas e suas soluções" (Escola, n.3, maio 1972, p.32). Os próprios editoriais produzem esse efeito, ao serem abertos com um repetido "Caro professor". Desse modo, dentre os leitores possíveis, o editorial recorta aquele que a revista privilegia e que é nomeado na expressão que complementa o nome da revista: Escola para professores. Ao professor, dirige-se mostrando-se sensibilizada com seus problemas e trazendo soluções que estão em suas páginas e que atribui aos próprios professores, de quem é porta-voz e intérprete. 


\section{As bANCAS DE JORNAL COMO ESTRATÉGIA DE CIRCULAÇÃo}

Como já indicado, um aspecto importante de diferenciação da revista Escola em relação a outros periódicos educacionais é a estratégia adotada pela Abril de difundir esse periódico e a própria reforma nas bancas de jornal, nas quais compartilha o espaço com a grande imprensa e seus noticiários e com revistas como Claudia, Veja e Quatro Rodas, dessa mesma editora. Oferecida ao olhar rápido do passante em busca de novidades, essa estratégia de venda e circulação de um periódico educacional tende a alterar radicalmente o lugar onde o professor procura e encontra o que nutre a sua cultura profissional. Esse lugar de circulação corresponde à alteração do padrão de materialidade dos periódicos educacionais, os quais até então costumavam se apresentar em formatos menores, com capas austeras, com poucas imagens ou mesmo nenhuma. A revista da Abril tem quase o dobro do tamanho de suas congêneres, muitas fotos e dispositivos de leitura que a tornam semelhante às revistas de bancas de jornal, promovendo assim práticas de leitura inusuais nesse tipo de periódico. São leituras próprias dos momentos de lazer e menos comprometidas com exigências laborais: leituras entrecortadas por subtítulos, boxes e imagens que permitem ao leitor saltar de uma parte a outra do texto, incitando uma leitura exploratória, ágil e rápida, por isso mesmo não exaustiva, em textos que procuram diminuir a aridez do tratamento de determinados temas, própria de boa parte da tradição dos periódicos dirigidos ao professor primário e secundário.

Numa primeira comparação entre Escola e os periódicos educacionais consagrados no meio educacional, de imediato sobressai o contraste em relação à quantidade de imagens, sobretudo fotos. Comparando somente as capas desse tipo de periódico, percebe-se também a multiplicidade de cores empregadas na revista da editora Abril. Se considerarmos publicações antigas, como Atualidades Pedagógicas e Revista do Magistério, ou do mesmo período que a revista Escola, como Didata, EBSA e Educação Hoje, percebe-se a utilização de apenas uma cor além do branco e preto. O colorido das capas de Escola é um chamariz importante em bancas de revista para um público leitor que, apesar de ser o mesmo, está sendo reconfigurado, sem que o professor-leitor se aperceba disso. No Brasil, em particular desde a década de 1960, entramos na época da imagem, com a televisão galgando um lugar cada vez mais preponderante nos hábitos das famílias. Televisão em cores, revistas coloridas, imagens em movimento. É o que também trazem as fotos da revista Escola. Nas primeiras dez capas desse periódico, por exemplo, predominam fotos, em geral de crian- 
ças realizando alguma atividade. No corpo das revistas, nas matérias, também há muitas fotos sugerindo movimento; ao contrário do que predomina em periódicos mais antigos, nos quais raramente sugere-se movimento, com fotos posadas de alunos e ou professores, fotos de edifícios escolares e outras. Nas páginas desses mesmos periódicos, tanto dos mais antigos quanto da maioria dos contemporâneos à revista Escola, há poucas fotos.

O chamariz das cores e das imagens em movimento é o que também ganha destaque em concurso organizado pela revista na sua edição $\mathrm{n}^{\circ} 14$, de abril de 1973 (p.21-22): "Quem quer ganhar um TV Colorado a cores". Com esse título, que ocupa duas páginas, Escola incita professores e alunos a participar de "um concurso de âmbito nacional" sobre este tema: "A importância da televisão para o aprimoramento do ensino no Brasil”. Nesse anúncio também há fotos. Numa delas, os alunos estão olhando uma TV colocada próximo à lousa de uma sala de aula, ao lado da escrivaninha do professor, o qual, aliás, está ausente. Em seu lugar, porém, está a TV, colocada sobre uma coluna que tem uma altura acorde com a estatura de um adulto e com uma imagem que é o rosto de um artista - aparentemente - em primeiro plano, como se fosse o professor. ${ }^{10}$ Confundido com a nova tecnologia, o professor-artista ainda parece estar lá, nessa figuração do humano que a coluna e a TV compõem, mas é claro que o seu lugar já foi tomado pelo novo apetrecho que Escola introduz - ao qual deveríamos somar todos os que são configurados em outras páginas e edições - e que a revista lhe oferece como prêmio. O periódico informa que no concurso poderão participar alunos do $1^{\circ} \mathrm{Grau}$, com trabalhos que deverão ter um mínimo de sessenta linhas. Tanto o aluno quanto o professor orientador do trabalho que fiquem em primeiro lugar ganharão uma TV colorida, mas, no caso do segundo lugar, apenas em branco e preto. Imagens em movimento e cores são o prêmio destinado tão-somente aos melhores. Nesse anúncio, por meio do mesmo jogo de espelhos que se observa em outras propagandas, fundem-se no mesmo ponto: a professora, Escola e a TV em cores - esta última representando o que há de mais moderno nas tecnologias de comunicação e, desse modo, o próprio regime militar, na medida em que remete a uma área sobre a qual o regime costumava alardear seus grandes feitos.

Na publicação da Abril observa-se que as fotos seguem critérios que são próprios do fotojornalismo. Elas parecem resultar de um procedimento em que o fotógrafo, como diz Mauad, adota o papel de testemunha ocular, posicionando-se como "testemunha desapercebida dos acontecimentos", de modo a transmitir certa naturalidade, certo ar espontâneo da cena que deverá ser fotografada, mesmo quando ela precisa ser montada. ${ }^{11}$ Outra característica 
dessa nova forma de fotografar, que corresponde a uma tendência que vem da década de 1940, quando se inicia uma mudança importante no padrão técnico e estético das revistas ilustradas, é a associação entre o texto e a imagem, como também é possível notar na revista Escola. ${ }^{12} \mathrm{Nesta}$, as próprias fotos por vezes tornam-se elementos centrais da narrativa, na medida em que a sua disposição reproduz uma sequência de ações que os textos escritos, ao lado de cada foto, procuram esclarecer, ampliar, redimensionar.

A nova forma de fotografar e de dispor as fotos possibilita que a imagem fotográfica elabore uma narrativa sobre os fatos, conforme indica Mauad ao tratar das transformações que se processaram com o fotojornalismo. E quando isso não é possível, encena-se a história (ibidem). O que importa, afinal, é a sensação de veracidade, como já mencionado; o leitor tem de acreditar no que está vendo, e o seu olhar tem de ser capturado pelo movimento e a realidade que as fotos supostamente reproduzem. Tudo isso está bem distante do papel atribuído às fotos nos periódicos dirigidos ao professor que predominavam no mesmo período ou antes da década de 1970. Em geral, o papel primordial de "capturar a atenção do leitor" ainda não é tão forte nem conta com a variedade de recursos observáveis na revista Escola (ibidem). Não há neles uma maior preocupação com a edição das imagens, nem com o seu tratamento articulado à palavra, como se observa na revista da Abril, na qual percebe-se uma íntima articulação entre imagem e escrita. Esses aspectos são apontados por Mauad quando faz o histórico das transformações ocorridas nas revistas ilustradas, sobre as quais também é importante destacar o surgimento do editor de fotografias - relacionado com a especialização de funções - e, ainda, o fato de as reportagens exigirem a presença de um fotógrafo junto ao jornalista. No caso da revista Escola, a ficha técnica relaciona vários fotógrafos e também menciona um setor responsável pelas fotografias, de início denominado "Serviços fotográficos" e depois "Estúdio Fotográfico". Nessa revista da Abril há uma evidente preocupação com as fotos, com os efeitos que elas podem produzir no leitor - efeitos de realidade e de movimento.

O movimento, na verdade, não está apenas nas fotos. Nos hábitos de leitura que as revistas comerciais criam, folhear sem compromisso é incitado pelo atrativo das fotos, do colorido, do encontro rápido com as novidades e as oportunidades oferecidas a quem se mantém atualizado. Com a revista Escola, o professor - ou melhor, a professora - é inserido nesse mesmo circuito e nele mistura-se com "Sancreme, a gordura magra", "Koleston, a primeira tintura creme", Capricho e outros tantos produtos que a revista da Abril oferece em suas páginas, em propagandas que também fazem o colorido da revista e 
deixam os olhos cheios de cores. A reforma de ensino entra nesse mesmo circuito, tornando-se também um produto da Abril oferecido com grande entusiasmo a seus professores-leitores.

Nesse surto de modernidade da década de 1970, nos anos de chumbo da ditadura, Escola promete manter seus leitores atualizados e, para tanto, a sua periodicidade é um elemento importante. Mensalmente, ela oferece a sua galeria de acontecimentos para que, à maneira do flâneur, o professor-leitor passeie por entre fotos e nomes. Nesse seu olhar distraído, vagueando entre as páginas da revista, o leitor pode ser capturado pelo acontecer pedagógico, por fotos que recriam o seu lugar, o lugar dos alunos e o da escola. E o recriam conforme uma materialidade que define também esse lugar. As fotos cumprem a esse respeito um papel fundamental. Elas produzem uma sensação permanente de movimento, deixam transparecer certa naturalidade e espontaneidade das atividades em foco, com crianças e jovens muito envolvidos no que estão fazendo, tudo apresentado de forma agradável, colorida e atraente, como se essa característica fosse da própria realidade à qual o leitor é remetido, embora seja, em primeiro lugar, um atributo da forma material. Dessa realidade faz parte a reforma. E a Abril não parece poupar esforços para torná-la atraente. Em sua divulgação há um forte investimento desde o primeiro número, até o momento em que essa opção mostra-se problemática, como posteriormente se observa em seus editoriais.

\section{A REPRESENTAÇÃO DA REFORMA NOS EDITORIAIS}

Nos editoriais - constantes até o $\mathrm{n}^{\circ} 19$, de setembro de 1973 -, costuma-se aludir ao que se destaca nas capas, aos conteúdos das matérias dispostas no número e a uma avaliação do que é a implantação da reforma. O editorial articula-se aos enunciados dos títulos das matérias, assim como aos textos introdutórios que as resumem, ordenando as práticas de leitura esperadas para o periódico.

Como já se indicou em relação aos primeiros números, a revista se refere à reforma de ensino de forma entusiástica. Além disso, começa a apresentar reportagens sobre trabalhos desenvolvidos em sala de aula de diferentes estabelecimentos de ensino como se fossem uma decorrência da reforma. Ao apresentar exemplos de aulas, atividades pedagógicas, métodos, exercícios, lições ou trabalhos e recursos desenvolvidos pelo professor, em diferentes séries e áreas (comunicação e expressão, ciência, matemática etc.), envolvendo alfabetização, educação física, linguagem oral, expressão corporal e matemática mo- 
derna, entre outras disciplinas, a revista Escola insere tudo isso no âmbito da reforma. Nas reportagens, as escolas selecionadas são apresentadas de modo breve, mencionando-se o nome, a localização e seu público, sem qualquer referência à sua história ou à sua perspectiva pedagógica, como neste exemplo:

"Hoje nós vamos falar de gente e este bonequinho representa cada um de vocês".

Os alunos acham graça no desenho que a professora Suely Arradi faz no quadro. Ele estará presente até o fim da aula.

Na quinta série da Escola Municipal Antônio Carlos de Abreu Sodré, em Vila Sabará (bairro de São Paulo), as aulas de estudos sociais são envolventes. O próprio tema é uma motivação e as crianças participam ativamente. ${ }^{13}$

O foco dessas matérias são as aulas acompanhadas pelos repórteres da revista. Nelas são apresentadas fotos que destacam diferentes aspectos e momentos da aula, são descritas as ações de professores e alunos e reproduzidas as suas falas:

"Será que vocês saberiam dizer quem é mais velho: o Hermes que tem sete anos ou a aniversariante que tem seis?"

"O Hermes", responderam as crianças em coro.

As crianças não sabem que, através do bate papo gostoso e descontraído, objetivos definidos foram alcançados. ${ }^{14}$

Desde o primeiro número até o ${ }^{\circ} 11$, essas matérias são claramente distinguidas porque fazem parte de uma seção fixa indicada no sumário e que pode ser localizada rapidamente por meio de um simples folhear da revista, graças a um dispositivo que consiste numa faixa lateral, preta ou de cor laranja, colocada na página que abre cada reportagem destinada a uma série. Todos esses números de Escola, à exceção do no 5 (jul. 1972), que corresponde a uma "edição especial", apresentam uma reportagem para cada série. Na parte superior da faixa que abre cada matéria, o leitor pode visualizar rapidamente a que série se refere a aula descrita. ${ }^{15}$

O destaque dado a essa seção fixa, com o dispositivo material que possibilita a sua rápida localização, tem como alvo principal o professor preocupado com as atividades a serem desenvolvidas com seus alunos. Ao professor, a revista procura mostrar que a reforma chegou à sala de aula. Para tanto é essencial o boxe presente nessas matérias. Cada reportagem relativa a uma série é encerrada com um pequeno boxe onde são mencionados os objetivos da aula, a 
função do professor, a relação da aula com determinada área curricular. Esse boxe é um dispositivo de leitura localizado no final da matéria, e a sua função precípua é o enquadramento da aula descrita nos termos e conceitos criados e mobilizados pela reforma. O silêncio sobre as características e a história dos estabelecimentos de ensino escolhidos é o dispositivo que permite ressignificar, por meio do boxe, o que é descrito na matéria como parte do processo de instauração da reforma. Eis dois exemplos sobre o tipo de texto presente nos boxes:

Nessa série, os alunos estudam como tema central a vida em sua cidade. A área de Estudos Sociais, que tem por objetivo o ajustamento pessoal e social do aluno à comunidade, pode ser tomada como núcleo de onde irradiam todas as áreas do currículo. ${ }^{16}$

A aula integrou conteúdos de comunicação e expressão e estudos sociais. Os seus objetivos foram: adquirir conhecimentos relacionados com aspectos históricos, econômicos e de folclore e arte da Bahia, utilizar esses conhecimentos relacionando fatos e personagens nas dimensões geográficas... ${ }^{17}$

O que nesses trechos figura como "áreas e objetivos da aula descrita" corresponde ao que também aparece na revista em entrevistas com autoridades e nos fascículos com os textos da reforma. Há toda uma linguagem disseminada nas páginas de Escola que opera de modo imperceptível, embebendo o professor-leitor na ambiência da reforma, com seus termos e modos de entender o ensino na escola. Fala-se nas áreas próprias da reforma, como estudos sociais e comunicação e expressão; utilizam-se os mesmos termos e expressões: "exercício consciente da cidadania", "cooperação", "convívio", "solidariedade", "ajustamento" do educando ao "meio" ou à "comunidade" etc. O dispositivo do boxe, presente nas matérias sobre atividades desenvolvidas pelo professor, cumpre a função de enquadrar a aula descrita no modelo curricular estabelecido pela reforma. Sutilmente, esse dispositivo de leitura (re)ordena os saberes escolares segundo a nova matriz curricular.

O tom que predomina nos editoriais dos primeiros números da revista, de elogio e entusiasmo em relação à reforma, logo começa a ceder em face das "controvérsias" que ela gera. Obrigada a ficar atenta às mudanças de seu público alvo, Escola faz eco a essas primeiras dissonâncias, como se observa neste editorial:

Os professores de História e Geografia estão alarmados com as suas perspectivas profissionais, à vista do problema colocado pela integração dessas disciplinas através de Estudos Sociais, nas oito séries do $1^{\circ}$ grau. História e Geografia 
têm futuro? Escola apresenta amplo debate a respeito, mostrando a amplitude da controvérsia e procurando situá-la dentro dos objetivos da lei da reforma. Outra controvérsia suscitada pela reforma é amplamente examinada neste número: é a dependência, assunto intimamente ligado à reprovação e recuperação dos alunos atrasados. (Escola, n.4, jun. 1972, p.3)

Nas matérias correspondentes a esses editoriais são apresentados argumentos a favor e contra, como se observa numa reportagem que tem este sugestivo título: "História e Geografia têm futuro?". Nela, a revista veicula as críticas de diferentes autoridades das áreas de História e Geografia sobre a nova lei.

Isso não significa que a revista deixe de tomar partido a favor da reforma, justificando-a, até mesmo, por meio da comparação com a LDB de 1961, como se observa neste editorial:

A Lei de Diretrizes e Bases da Educação, de 1961, traduzindo as expectativas do governo e da organização do ensino, foi bastante ambiciosa naquilo que pretendia a respeito da formação dos professores responsáveis pelo ensino fundamental. Infelizmente, o tempo encarregou-se de demonstrar que seus objetivos dificilmente seriam atingidos e, de fato, não o foram. A nova lei de Diretrizes e Bases, a lei 5692, mais adequada à realidade nacional, pretende alcançar metas mais modestas quanto à formação de novos professores e à qualificação e atualização daqueles que estão em exercício, e abriu perspectivas mais viáveis para a consecução dos seus objetivos. (Escola, n.6, ago. 1972, p.3)

A partir do no 8 da revista observa-se um crescente distanciamento em relação à reforma, perceptível nos editoriais. Nesse número, precisamente no mês em que se comemora o dia do professor, Escola decide fazer uma "pesquisa" entre seus leitores. Segundo o editorial, sempre dirigido ao "Caro Professor", com essa pesquisa "quer conhecer seus leitores", "saber quem você é e o que você espera da nossa revista" (Escola, n.8, out. 1972, p.3). E mais do que isso, Escola quer ter o professor junto a ela, fazendo a revista, conforme destaca o título do formulário para realizar a pesquisa presente nessa edição: "Professor, vamos fazer juntos esta revista?" (idem, p.23). O professor é então convidado a escolher dez assuntos por ordem de preferência, de um total de quarenta, para serem objeto das suas reportagens. Eis os trechos iniciais do convite feito pela revista:

Esta revista é sua. Portanto, é justo que também você faça parte da equipe que seleciona os assuntos destinados à publicação em Escola. 
O mais comum é abrirmos uma revista com artigos e reportagens que não escolhemos. E nem sempre aquilo que lemos é o que gostaríamos de ler. (ibidem)

Evidentemente, está-se falando da própria revista, que talvez não estivesse obtendo sucesso entre seu público destinatário. Como explicita o enunciado, reportagens e artigos parecem não atender às expectativas dos docentes. Ao realizar essa pesquisa, a revista usa uma estratégia semelhante à que empregou quando foi lançada, pois busca identificar-se com o leitor e envolvê-lo na mudança da sua linha editorial, que aparentemente procura se distanciar da reforma. Esse distanciamento também pode ser observado nos assuntos elencados pela revista para escolha do professor. Dos quarenta temas, apenas dois concernem à reforma: "profissionalização e a reforma", "a reforma vai bem". Apesar de o convite para participação na pesquisa ter sido feito ao professor no editorial desse número, nos editoriais subsequentes não há mais qualquer referência a ela.

A partir do número 10, de dezembro de 1972, a reforma deixa de ser lembrada nos editoriais. E, coincidentemente, a revista destaca no seu editorial a "presença polêmica" do professor Dermeval Saviani. Na entrevista feita com Saviani o tema principal é a lei 5692/71.

Do número 15 em diante, o editorial perde a sua função de interlocução com o leitor, tornando-se um complemento do sumário. Deixa de ser assinado pelo editor, Wladimir Araújo, que permanece como diretor de redação até o número 20 e é substituído no número seguinte por Chico Santa Rita. Ainda no número 15 (maio de 1973), desaparece o "Caro professor", um indício do próprio desaparecimento dos leitores e da curta sobrevida do periódico, que acaba no ano seguinte, no número 27. O "Caro professor" reaparece apenas no último número, quando a revista despede-se de seus leitores.

A revista Escola, apesar da sua tentativa de se atrelar às políticas educacionais do regime militar e de procurar se adaptar ao seu público, foi um fracasso do ponto de vista comercial e de seu impacto no campo educacional. Os dados disponíveis atestam esse fato: a tiragem inicial era de 67 mil exemplares, seu último número foi editado com uma tiragem de 25 mil exemplares. ${ }^{18} \mathrm{~A}$ própria carta do diretor de redação, quando do encerramento do periódico, em abril de 1974, afirma:

Ao suspendermos a publicação da revista Escola, temos a mesma sensação frustrante do mestre que não conseguiu dar uma determinada aula por lhe faltarem os materiais necessários. No nosso caso, essa interrupção é causada de um lado pelo violento aumento de custo de papel, decorrente da crise mundial de 
matérias-primas, e de outro, pela necessidade de redefinirmos os objetivos e a política editorial da revista. (Escola, n.26, abr. 1974)

Em relação à política editorial de Escola, não há dúvida de que o seu atrelamento à reforma de ensino não garantiu a boa recepção esperada pela revista. É bem provável até que o efeito tenha sido o contrário, em face da resistência de professores à própria reforma, com tudo o que ela implicava, como a unificação dos níveis e de tradições distintas, sem contar a rejeição à própria ditadura. Mas também é preciso considerar a diferença desse periódico em relação ao padrão vigente de periódicos destinados aos docentes primários e secundários (das décadas de 1950 e 1960) e a sua semelhança às outras revistas comerciais da Abril. Por exemplo, no que diz respeito à autoria, as matérias em geral não identificam o autor e são produzidas por jornalistas, ao contrário do que se observa na maioria dos periódicos educacionais da época ou nos anteriores, com textos produzidos por professores e outros profissionais da educação, com a identificação clara do autor. Outra característica é o tipo de práticas de leitura que a publicação da Abril propicia. Estaria a rejeição voltada às novas práticas de leitura instituídas com a sua fórmula editorial, com nítido perfil de revista comercial e que embaralhava fronteiras, apagando distinções e hierarquias que os periódicos destinados ao professor demarcavam? Nesse período, com esse tipo de publicação que a editora Abril produz e impulsiona, é forjado um novo professor-leitor de periódicos educacionais, um leitor afeito aos padrões da indústria cultural e que somente deverá vingar na década seguinte. Prova disso é a bem-sucedida revista que sucede à Escola na década de 1980, cujo nome, Nova Escola, é bem sugestivo a respeito dessa herança.

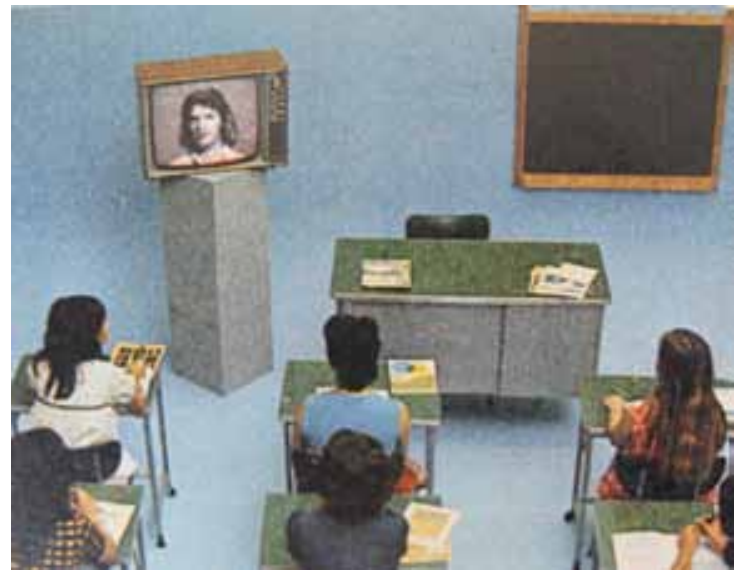

Figura 1 - Escola, n.14, abr. 1973, p.21. 


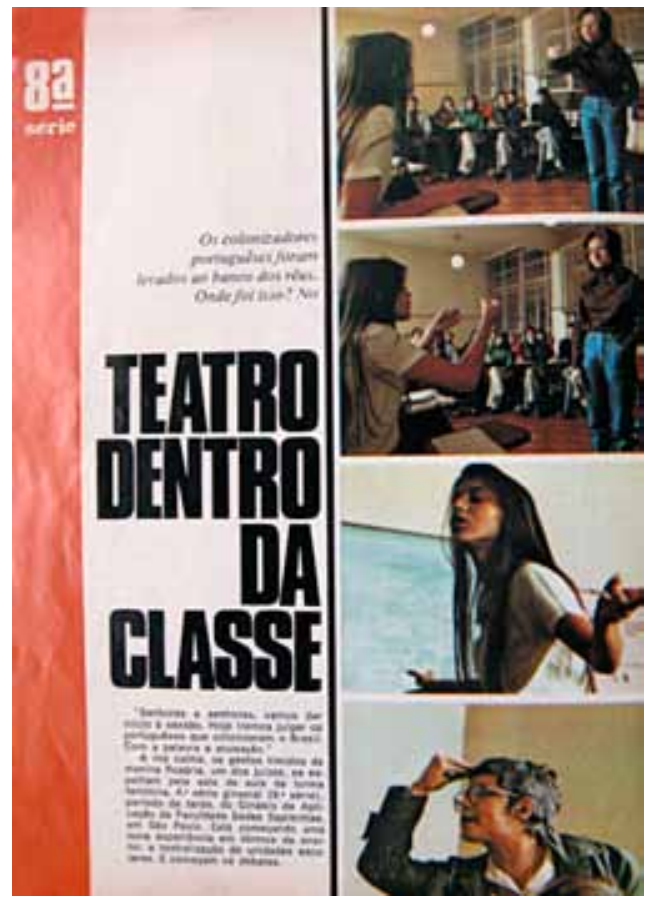

Figura 2 - Escola, nº 0, out. 1971, p.58.

\section{NOTAS}

${ }^{1}$ Ver, por exemplo, NAGLE, Jorge. A reforma e o ensino. São Paulo: Edart, 1973.

${ }^{2}$ Cf. CARVAlHO, Marta M. C. de; TOLEDO, Maria Rita de A. A constituição da "forma escolar" no Brasil: produção, circulação e apropriação de modelos pedagógicos. São Paulo: Edusp; Ed. Unifesp, 2003, p.4. Sobre modelos de impressos pedagógicos, ver CARVALHO, Marta M. C. de. A escola e a República e outros ensaios. Bragança Paulista (SP): Edusf, 2003.

${ }^{3}$ Cf. CERTEAU, Michel de. L'invention du quotidien. 1. Arts de faire. Paris: Gallimard, 1990, p. 60.

${ }^{4}$ Para Chartier, "por um lado, a leitura é prática criadora, atividade produtora de sentidos singulares, de significações de modo nenhum redutíveis às intenções dos autores de textos ou fazedores de livros ... Por outro, o leitor é, sempre, pensado pelo autor, pelo comentador e pelo editor como devendo ficar sujeito a um único sentido, a uma compreensão correta, a uma leitura autonomizada. Abordar a leitura é, portanto, considerar, conjuntamente, a irredutível liberdade dos leitores e os condicionamentos que pretendem refreá-la. Esta tensão fundamental pode ser trabalhada pelo historiador através de uma dupla pes- 
quisa: identificar a diversidade das leituras antigas através de seus esparsos vestígios e reconhecer as estratégias através das quais autores e editores tentavam impor uma ortodoxia do texto, uma leitura forçada. Dessas estratégias, umas são explícitas, recorrendo ao discurso (nos prefácios, advertências, glosas e notas), e outras implícitas, fazendo do texto uma maquinaria que, necessariamente, deve impor uma justa compreensão". Ver CHARTIER, Roger. A história cultural: entre práticas e representações. Lisboa/Rio de Janeiro: Bertrand/Difel, 1990, p.123.

${ }^{5}$ Entende-se aqui que a criação de uma nova categoria docente deve-se, de um lado, à conversão dos professores primários e dos professores do ginásio em professores de $1^{\circ}$ grau; de outro, à reorganização da formação docente com as licenciaturas curtas (no caso dos professores de $5^{\mathrm{a}}$ a $8^{\mathrm{a}}$ séries) e à supressão das escolas normais pela habilitação em magistério.

${ }^{6} \mathrm{~A}$ análise e o detalhamento da fórmula editorial aqui apresentada baseia-se no trabalho de REVAH, Daniel; TOLEDO, Maria Rita de A. O regime militar na (des)memória da Abril: a revista Escola e a difusão da 5692/71. In: História da educação. Pelotas (RS): UFPel, 2010. (no prelo)

${ }^{7}$ Expressão dessa transformação é a seção fixa intitulada "O ensino é notícia", na qual se faz veicular pequenas notas sobre acontecimentos do momento, como "censo escolar", "calendário escolar" e "seminários para professores".

${ }^{8}$ Ver AMARAL, Luis. Técnica de jornal e periódico. Rio de Janeiro: Tempo Brasileiro, 1969, p.60-61.

${ }^{9}$ Só há autoria nos editoriais e nos números especiais, como Escola n.5.

${ }^{10}$ Ver a Figura 1.

${ }^{11}$ MAUAD, A. M. O olho da história: fotojornalismo e história contemporânea. Disponível em: www.comciencia.br/reportagens/memoria/12.shtml, 2004. Acesso em: 15 out. 2009.

${ }^{12}$ Mauad atribui o pioneirismo dessa mudança à revista O Cruzeiro. Na década de 1940, essa publicação "reformulou o padrão técnico e estético das revistas ilustradas apresentando-se em grande formato, melhor definição gráfica, reportagens internacionais elaboradas a partir dos contatos com as agências de imprensa do exterior e, em termos estritamente técnicos, a introdução da rotogravura, permitindo uma associação mais precisa entre texto e imagem" (idem). Sobre o fotojornalismo, ver: GODOY, Alexandre P. Ver para crer: na Última Hora. In: Histórica - Revista eletrônica do arquivo público do Estado de São Paulo, n.31, 2008; COSTA, Helouise L. Aprender a ver as coisas: fotojornalismo e modernidade na revista O Cruzeiro. Dissertação (Mestrado) - ECA-USP. São Paulo, 1992.

${ }^{13}$ Cf. "A vida de cada aluno é um ótimo exemplo", Escola, n.3, maio 1972, p.54.

${ }^{14}$ Cf. "Veja como você pode conhecer seus alunos", Escola, n.2, abr. 1972, p.47.

${ }^{15}$ Veja-se um exemplo na Figura 2, onde se reproduz uma página do exemplar n.0, de out. 1971. Posteriormente, a partir do n.8, a faixa é substituída por uma forma oval colocada na parte superior esquerda da folha, de um tamanho que torna a sua visualização menos imediata. Logo abaixo dessa forma oval ou no seu interior é indicada a série. Essa seção fixa, do 
pré à $8^{\mathrm{a}}$ série, que apresenta uma reportagem para cada série, deixa de existir a partir do n.12. Mas, a partir do n.13 (mar. 1973), surge a seção "plano de ensino", que parece vir em substituição à anterior, apresentando inclusive um dispositivo semelhante para facilitar a sua rápida localização na revista: um retângulo com o nome da seção escrito no seu interior, na parte superior esquerda da página. Essa nova seção fixa desaparece no n.22, em dez. 1973.

${ }^{16}$ Cf. “De onde vem essa comida?”, Escola, n.10, dez. 1972, p.47.

${ }^{17}$ Cf. “Até Caymmi entrou nesta transa”, Escola, n.10, dez. 1972, p.53.

${ }^{18}$ Cf. ROSENBERG, Lia; BARBOSA, José J.; PARRA, Márcia L. V.; CARBONE, Célia R. Publicações para professor: um estudo de caso. Cadernos de Pesquisa, São Paulo: Fundação Carlos Chagas, n.30, p.57-64, 1979.

Artigo recebido em outubro de 2010. Aprovado em dezembro de 2010. 